\title{
Population-based cohort study on the risk of malignancy in East Asian children with Juvenile idiopathic arthritis
}

Victor C Kok ${ }^{1,2}$, Jorng-Tzong Horng ${ }^{1,3^{*}}$, Jing-Long Huang ${ }^{4,5^{*}}$, Kuo-Wei Yeh ${ }^{4}$, Jia-Jing Gau ${ }^{3}$, Cheng-Wei Chang ${ }^{6}$ and Lai-Zhen Zhuang ${ }^{3}$

\begin{abstract}
Background: To investigate the association and magnitude of risk between JIA, its associated treatment and cancer development in Taiwanese children.

Methods: Nationwide population-based 1:4 age- and gender-matched retrospective cohort study was designed using the National Health Insurance Research Database of Taiwan. A cohort of 2,892 children $<16$ years old with JIA was formed as well as a non-JIA cohort of 11,568 in year 2003 to 2005. They were followed up till a diagnosis of malignancy or up to 8 years until 2010. Relative risk (RR), incidence rate ratio (IRR), and adjusted hazard ratio (aHR) of developing malignancy were calculated.

Results: The female to male ratio was 0.79:1. There were 3 cases of incident cancer in the "MTX use, biologics-naïve" group, only 1 in the anti-TNF biologics-containing group and 29 in the "both MTX-and biologics-naïve" group, in comparison, there were 50 cases of cancer in the non-JIA comparator group. During a 16114.16 patient-years follow-up, the RR and IRR for developing a malignancy in both methotrexate- and anti-tumor necrosis factor (TNF) biologics-naïve JIA children were 2.75 (95\% confidence interval, $1.75-4.32)$ and 3.21 (2.01 - 5.05), respectively. For leukemia, the IRR was 7.38 (2.50 - 22.75); lymphoma, 8.30 (1.23 - 69.79); and soft tissue sarcoma, 11.07 (0.84 - 326.4). The IRR of other cancers was $2.08(1.11$ - 3.71). The aHR on cancer risk was $3.14(1.98-4.98)$ in methotrexate- and biologics-naïve group. There were no statistically significant increased risk in JIA patients treated with methotrexate and/or anti-TNF biologics.
\end{abstract}

Conclusions: Compared with children without JIA, children with JIA have 3-fold increase of risk on malignancy in East Asia. Seemingly neither methotrexate nor anti-TNF biologics increases the risk further.

Keywords: Arthritis, Juvenile rheumatoid (MeSH), Juvenile idiopathic arthritis, Neoplasms (MeSH), Risk (MeSH), Cohort studies (MeSH)

\section{Background}

Juvenile idiopathic arthritis (JIA) is a spectrum of several heterogeneous disorders manifested mainly as chronic inflammatory arthritis with no identifiable etiology with an onset before the age of 16 years. The older terms, juvenile rheumatoid arthritis (JRA) and juvenile chronic arthritis (JCA) have been replaced by the term juvenile

\footnotetext{
*Correspondence: horng@db.csie.ncu.edu.tw; hjlong0182@gmail.com 'Population-Health and Clinical Informatics Research Group, Department of Biomedical Informatics, Asia University Taiwan, Taichung, Taiwan

${ }^{4}$ Division of Paediatric Allergy Asthma and Rheumatology, Department of Paediatrics, Chang Gung Memorial Hospital, Linkou, Taiwan

Full list of author information is available at the end of the article
}

idiopathic arthritis which is a more inclusive term than JRA [1].

Approximately 1 in every 1000 children worldwide has JIA $[2,3]$. The best available annual incidence rate for JIA in the West is from a UK study which provided an estimate at 10/100,000 [4]. JIA appears to be less common in African-American and Asian populations [5]. A population-based study in Taiwan demonstrates that the prevalence of JIA in Taiwan is $3.7 / 100,000$, which is higher than the prevalence in Japan, but lower than that in the West [6]. In addition to this ethnic difference in prevalence, previous studies revealed that the age of 
onset and gender differences in JIA are different between Caucasians and Asian children [6-8]. In our previously reported community-based cohort study of the clinical features in children with JIA in selected regions of Taiwan using the International League of Associations for Rheumatology system (ILAR) classification criteria, a remarkably high prevalence was found in the enthesitis-related arthritis (ERA; 37.4\%) of the Chinese cohort, but a relatively low rate of uveitis $(6.7 \%)$ as compared with previous reports on Western populations [9].

The first line treatment for JIA usually contains nonsteroidal antiinflammatory drugs (NSAIDs) and/or intraarticular glucocorticoid injection for controlling inflammation. Disease-modifying antirheumatic drugs (DMARDs), usually used in second line, are comprised of methotrexate (MTX) (conventional) and tumor necrosis factor (TNF-alpha) inhibitors (biologics) [10-14]. The criteria for escalation of therapy can be found in the paper published by the American College of Rheumatology elaborating the evidence-based recommendations for the treatment of JIA [15].

Two recent reports, one from the Canadian JIA registries maintained by paediatric rheumatology centers (JIA children $=1,834$ ) and another from a Scottish nationwide population-based inpatient cohort $(\mathrm{n}=349)$, showed no increase of risk for cancer over long-term follow-up $[16,17]$. Nevertheless, three other recent studies notably showed increased risks of malignancy in patients with JIA [18-20].

Therefore, the aim of the present study was to estimate the magnitude of the risk of cancer in East Asian population of JIA and to examine the risk of cancer in children with JIA to the general population according to their treatment allocation.

\section{Methods \\ Study design}

This study was designed as a population-based retrospective cohort study using data from a national administrative database with 1:4 gender- and age-matched comparators followed up to 8 years or until a diagnosis of malignancy was given. Figure 1 is a study flow chart demonstrating the design.

\section{Study population}

The study population was targeted from the Taiwan National Health Insurance Research Database (NHIRD). The NHIRD has been described in-depth in our previous studies [6,21-26]. In short, Taiwan National Health Insurance (NHI) program commenced on 1 March 1995. As of 2007, 98.4\% of Taiwan's population (22.96 million individuals) were enrolled in this program. The NHIRD provided to researches for academic research purposes contains a number of large computerized databases that incorporate registration files and relational original data on claims' reimbursement. These data files are de-identified by scrambling the identification codes of both the individuals and medical facilities and access to the files including data-mining and data-manipulation shall strictly comply with the Taiwan Personal Information Protection Act.

\section{Case definition and definition of diseases/conditions}

In Taiwan, paediatric rheumatologists prefer to use the ILAR classification criteria for making a diagnosis of JIA [27]. Grouping of ICD-9-CM codes can be mapped to the ILAR categories in patients under the age of 16: 714.2 (systemic arthritis), $714.30+714.31$ (polyarthritis), $714.32+714.33$ (pauciarthritis or oligoarthritis, persistent and extended), 720.0 alone or $(720.0+714.0)$ or $(720.0+$ 714.3) (ERA), 696.0 (psoriatic arthritis).

A diagnosis of JIA in this study requires 3 components, age less than 16 years, at least 3 times of reimbursement claims made by a paediatric rheumatologist(s) or a paediatrician(s) using any of the abovementioned ICD-9-CM codes with the first and the third claim being 6 months apart.

\section{Study cohorts}

From 2002 and 2010, we were able to identify all children less than 16 years old that diagnosed with JIA $(n=7,254)$. From these JIA children over a period of 9 years, we selected 2,912 children with JIA in years 2003 to 2005 . Then children with JIA who had already been given a diagnosis of malignancy were excluded $(n=20)$. The criterion for this exclusion required only a single claim with a cancer ICD-9-CM code traceable back to at least one whole year in the medical record so that the accrual of patients were actually having no prevalent cancer. This left a group of children $<16$ years old with JIA but having no evidence of malignancy $(\mathrm{n}=2,892)$ which became the JIA cohort for this study.

For forming a non-JIA comparator cohort, we did a 1:4 age- and sex-match for children with neither JIA nor cancer diagnosis traceable to the previous one year from the same period, 2003 to 2005. The index date for the comparator cohort was the earliest claim record. The non-JIA control group consisted 11,568 children.

\section{Grouping of JIA patients by treatment modalities}

In the period of 2003 to 2005, there were 2 kinds of TNF-alpha inhibitor reimbursed by the NHI Taiwan for children with JIA, namely, etanercept and adalimumab. In the JIA cohort, three distinct groups could be separated by treatment allocation: biologics-naïve methotrexate group, anti-TNF biologics-containing group, and both methotrexate- and biologics-naïve group.

Treatment with TNF-alpha inhibitors was categorized as ever exposed versus never exposed. Once exposure to a 
From NHIRD between 2002 and 2010

Select children ( $<16$ years old) with

$$
\text { JIA, } n=7,254
$$

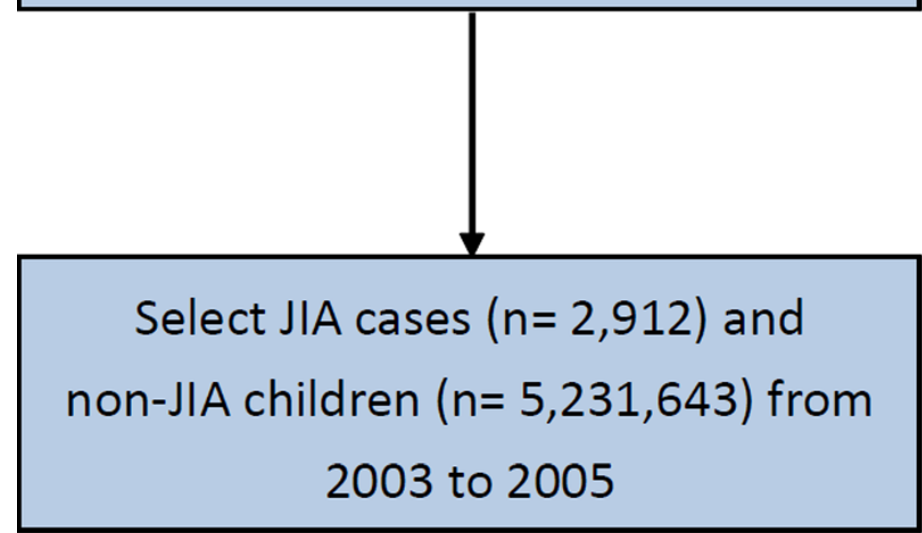

Exclude cases with malignancy traceable to $2002(n=2,443)$

Forming 1:4 age- and sex-matched cohorts with JIA $(n=2,892)$ and non-JIA $(n=11,568)$

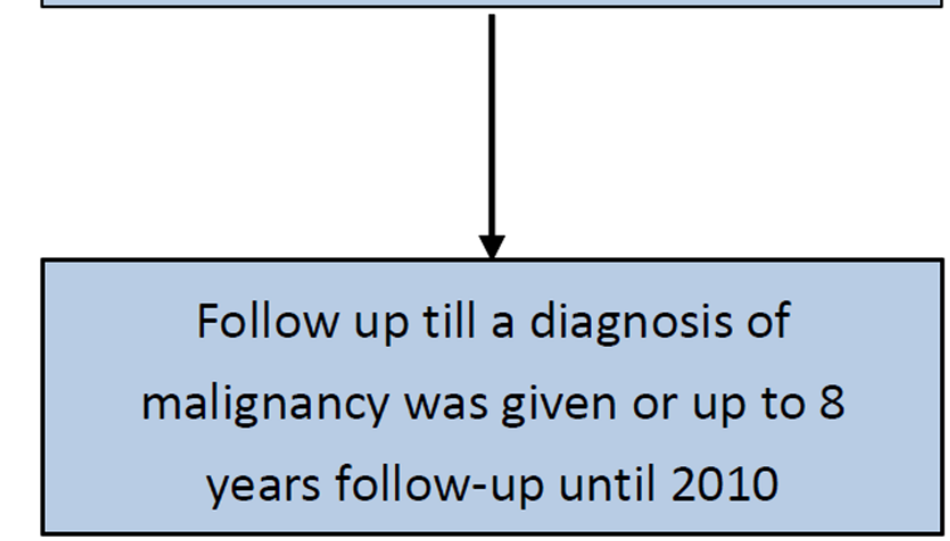

Figure 1 Retrospective cohort study design and study flow chart. NHIRD: National Health Insurance Research Database Taiwan; JIA: Juvenile idiopathic arthritis equivalent. 
TNF-alpha inhibitor was found, the status of "ever exposed" was maintained during the study follow-up. The persontime data for each therapeutic agent category did not include the person-time before the commencement of prescription of either MTX (in the biologics-naïve MTX group) or TNF-alpha inhibitors. Basically, the group being both methotrexate- and biologics-naïve can be regarded as children with JIA having no exposure to methotrexate or TNF-alpha inhibitors, thus the risk factor can be considered to be the diagnosis of JIA.

\section{Outcomes by identification of cancer cases}

Each patient and control in the study was followed up to a maximum of 8 years through the NHIRD from accrual to identify whether the studied individual received a cancer diagnosis. The diagnostic accuracy of a specific kind of malignancy was confirmed by both a specific ICD-9CM code within 140 to 208 given at least 3 times in different medical visits and inclusion into the Registry for Catastrophic Illness Patient Database (RCIPD). The index date was set on the date of the firstly detected code amongst three times claims using any one of the JIA ICD-9-CM codes.

\section{The scope and procedures of the search for the studies to be considered in the systematic review}

We conducted a systematic review of the literature on the risk of cancer in children with JIA and whether the risk would further be increased after exposure to DMARDs. The criteria for inclusion of published studies for the review were cohort studies examining risk of cancer in terms of relative risks (RR), incidence rate ratio (IRR), or standardized incidence ratio (SIR), in children with JIA no matter receiving any kinds of treatment for JIA. We performed literature search in PubMed and DOAJ (the Directory of Open Access Journals) using medical subject headings $(\mathrm{MeSH})$ terms combined with Boolean logics. The period of time covered by the literature search was from as early as the PubMed or DOAJ has covered until September of 2013. Table 1 outlines the result of this systematic review.

\section{Statistical analysis}

SAS statistical package (SAS System for Windows, version 8.2, SAS Institute, Cary, NC, USA), SPSSsoftware (version 17.0, IBM Inc., Chicago, Illinois, USA) and StatsDirect statistical software (StatsDirect Ltd, England, 2008) were used. The risk for cancer associated with JIA and various DMARDs exposure was evaluated and presented as a cumulative incidence ratio (RR) and HR in Cox regression. The RR which will not be influenced by immortal time was presented along with IRR. All statistical tests were two-sided. Values of $P<0.05$ were considered statistically significant. Cox models providing adjusted HR (aHR) included age, gender, and treatment modality as covariates. HRs with a 95\% confidence interval were calculated. The RR of cancer development were calculated and analyzed by Chi-square test $(2 \times 2)$. In addition, the impact of risk factors (how much disease burden is caused by certain risk factors) was also presented using the population attributable risk percent (PAR\%) with 95\% confidence interval in certain conditions.

This study has been approved by the Ethics Committee of Chang Gung Memorial Hospital Taiwan.

\section{Ethics statement}

Because this study used only NHIRD data files that were de-identified by scrambling the identification codes of both individuals and medical facilities, this research fits the criteria for exemption from a full review by the Institution Review Board contained within the legal statements promulgated by the Ministry of Health and Welfare of Taiwan pursuant to Paragraph 1, Article 5 of the Human Subjects Research Act enacted on December 28,2011 . This study adhered to strict confidentiality guidelines that are in accordance with the regulations set forth by the Personal Information Protection Act of Taiwan, amended on May 26, 2010. The research was conducted in accordance with the Declaration of Helsinki as revised in 1989.

\section{Results}

\section{Demographic characteristics of the JIA cohort}

In the JIA cohort $(\mathrm{n}=2,892)$, there were 1,618 boys and 1,274 girls. The female to male ratio was 0.79: 1 . Most of the patients $(n=1,960,67.8 \%)$ with JIA were in the age group of 11-15, 699 (24.2\%) in age group 6-10, and 233 (8\%) were in age group 0-5 (Table 2). Our results showed that the mean age of children with JIA assigned to the anti-TNF biologics group (mean, 10.54 years) were significantly younger than the other two groups, namely, biologics-naïve MTX group with mean age at 11.22 and both MTX- and biologics-naive group, 11.55 (Table 3).

In the JIA cohort, 344 patients, approximately $12 \%$, were treated with methotrexate but were TNF-alpha inhibitor-naïve. One hundred and twelve patients (3.9\%) required a TNF-alpha inhibitor to control their disease; $93.75 \%$ of them $(n=105)$ were previously or currently treated with methotrexate. Forty patients (1.4\%) of JIA patients were treated with non-biologic DMARDs other than methotrexate which can possibly be sulfasalazine, hydroxychloroquine, leflunomide, azathioprine and/or cyclosporin in this country (Table 3 ).

The mean duration of follow-up for the JIA cohort was 6.40 (SD 1.44) years and 7.78 (SD 0.59) in non-JIA cohort. 
Table 1 Outline of the results of the systematic literature review of the risk of malignancy in individuals with juvenile idiopathic arthritis

\begin{tabular}{|c|c|c|c|c|c|c|}
\hline $\begin{array}{l}\text { Authors/Year } \\
\text { published }\end{array}$ & $\begin{array}{l}\text { Study setting/number of JIA } \\
\text { patients }\end{array}$ & $\begin{array}{l}\text { Outcome } \\
\text { measure }\end{array}$ & Risk in JIA cohort & $\begin{array}{l}\text { Risk in MTX exposed, } \\
\text { biologics-naïve }\end{array}$ & $\begin{array}{l}\text { Risk in TNF-alpha } \\
\text { inhibitor exposed }\end{array}$ & Ref. \\
\hline Beukelman T et al/2012 & $\begin{array}{l}\text { Using national Medicaid } \\
\text { data/7,812 }\end{array}$ & SIR & $\begin{array}{l}\text { The SIR was } 4.4(95 \% \mathrm{Cl}, 1.8-9.0) \text { for probable } \\
\text { and highly probable incident malignancies. The } \\
\text { unexposed (to both non-biologic and biologic } \\
\text { DMARDs) group: the } \mathrm{SIR}=6.9(2.3-16) \text {. }\end{array}$ & $S I R=3.9(95 \% \mathrm{Cl} 0.4-14)$ & $\begin{array}{l}\text { Following any use of } \\
\text { TNF inhibitors, SIR was } \\
0 \text { ( } 95 \% \text { Cl } 0-13) \text {. }\end{array}$ & 20 \\
\hline Simard JF et al/2010 & $\begin{array}{l}\text { Nationwide cohort study through } \\
\text { linkage with the Swedish Patient } \\
\text { Register/5,296 }\end{array}$ & RR & \multicolumn{2}{|c|}{$\begin{array}{l}\text { Subjects with JIA (biologics-naïve) identified in } 1987 \text { beyond }(n=5,296) \\
\text { was significantly associated with incident lymphoproliferative malignancies } \\
\text { (RR 4.2, 95\% Cl 1.7-10.7) and cancers overall (RR 2.3, 95\% Cl 1.2-4.4). }\end{array}$} & - & 18 \\
\hline Nordstrom BL et al/2012 & $\begin{array}{l}\text { Large claims database American } \\
\text { cohort study/3,605 }\end{array}$ & $I R, S I R$ & \multicolumn{2}{|c|}{$\begin{array}{l}\text { The IRs of probable or highly probable cancer: } 67.0(95 \% \mathrm{Cl}, 1.3-132.5) \\
\text { cases/100,000 PY for biologics-naïv JIA and } 23.2(12.2-34.2) \text { cases/100,000 } \\
\text { PY for non-JIA. The JIA cohort had an elevated SIR of } 4.0(95 \% \mathrm{CI} 2.6-6.0) \\
\text { above SEER rate. }\end{array}$} & & 19 \\
\hline Kok VC et al/this study & $\begin{array}{l}\text { Nationwide population-based } \\
\text { Retrospective cohort study/2,892 }\end{array}$ & $\mathrm{RR}, \mathrm{IRR}$ & $\begin{array}{l}\text { The RR and IRR for developing a malignancy in } \\
\text { JIA individuals who were both MTX-and anti-TNF } \\
\text { biologics-naïve were } 2.75(95 \% \mathrm{Cl}, 1.75-4.32) \text { and } \\
3.21 \text { ( } 95 \% \mathrm{Cl}, 2.01-5.05) \text {, respectively, with the } \\
\text { population attributable risk of } 23.38 \% \text { ( } 95 \% \mathrm{Cl} \text {, } \\
10.56-36.21) \text {. For leukemia, the RR was } 6.33 \\
\text { (2.30 - 17.44); lymphoma, } 7.12(1.42-35.61) \text {; and } \\
\text { soft tissue sarcoma, } 9.50(1.24-72.46) \text {. The aHR on } \\
\text { cancer risk was } 3.14(1.98-4.98) \text { in MTX- and } \\
\text { biologics-naïve group. }\end{array}$ & No further increase in risk & $\begin{array}{l}\text { No further increase } \\
\text { in risk }\end{array}$ & This study \\
\hline Bernatsky S et al/2011 & $\begin{array}{l}\text { JIA registries at } 3 \text { Canadian } \\
\text { pediatric rheumatology } \\
\text { centers } / 1,834\end{array}$ & SIR & \multicolumn{2}{|c|}{$\begin{array}{l}\text { Only one invasive cancer was identified in individuals with JIA observed for } \\
\text { an average of } 12.2 \text { (SD 7.8) years (observation period: } 1974-2006) \text {. SIR }=0.12 \\
\text { ( } 95 \% \text { Cl, } 0.0-0.7) \text {. The risk of invasive cancers overall is NOT increased. No } \\
\text { further information on its relationship to drug exposure. }\end{array}$} & & 16 \\
\hline Thomas E et al/ 2000 & $\begin{array}{l}\text { Scottish nationwide population- } \\
\text { based inpatient cohort/896 }\end{array}$ & SIR & \multicolumn{2}{|c|}{$\begin{array}{l}\text { SIR in boys JIA with 2,647 person-years at risk: } 1.29 \text { (95\% Cl, 0.14-4.64); girls JIA with 3,940 } \\
\text { person-years at risk, } 0.83 \text { ( } 95 \% \mathrm{Cl}, 0.09-3.01) \text {./Not increased }\end{array}$} & - & 17 \\
\hline
\end{tabular}

Cl: confidence interval; IR: incidence rate; IRR: incidence rate ratio; JA: juvenile idiopathic arthritis; MTX: methotrexate; RR: relative risk; SIR: standardized incidence ratio; anti-TNF: anti-tumor necrosis factor. Selected studies are arranged top down by decreasing number of patients in the JIA cohort. 
Table 2 Demographic data of JIA and non-JIA children in this cohort study

\begin{tabular}{|c|c|c|c|}
\hline & & JIA $(n=2,892)$ & Non-JIA $(n=11,568)$ \\
\hline \multirow[t]{2}{*}{ Gender } & Boys & 1,618 & 6,472 \\
\hline & Girls & 1,274 & 5,096 \\
\hline Female : male ratio & & $0.79: 1$ & $0.79: 1$ \\
\hline \multirow[t]{3}{*}{ Age Group } & $0-5$ & 233 & 932 \\
\hline & $6-10$ & 699 & 2,796 \\
\hline & $11-15$ & 1,960 & 7,840 \\
\hline \multicolumn{4}{|c|}{ Type of JIA by ILAR criteria } \\
\hline & Polyarthritis & 377 & NA \\
\hline & Pauciarthritis or oligoarthritis (persistent and extended) & 136 & NA \\
\hline & Enthesitis-related arthritis & 1221 & NA \\
\hline & Psoriatic arthritis & 62 & NA \\
\hline & Systemic & 6 & NA \\
\hline & Unclassifiable & 1096 & NA \\
\hline \multirow[t]{2}{*}{ Years of follow-up } & Mean (SD) & $6.40(1.44)$ & $7.78(0.59)$ \\
\hline & Person-years at risk & $18,530.97$ & $89,156.74$ \\
\hline
\end{tabular}

Abbreviations: DMARDs: Disease modifying anti-rheumatic drugs; ILAR: the International League of Associations for Rheumatology; JIA: juvenile idiopathic arthritis; MTX: methotrexate; NA: not applicable; SD: standard deviation; TNF: tumor necrosis factor.

It is noteworthy of the marked difference in male to female ratio in East Asian children as compared to Caucasians.

\section{Risk of cancer}

Compared to non-JIA children during 89156.74 patientyears at risk, children with JIA who were MTX- \& biologics-naïve during 16114.16 patient-years at risk had significantly elevated RR for incident malignancy associated with JIA and IRR at 2.75 (95\% CI $1.75-4.32$ ) and 3.21 (95\% CI $2.01-5.05)$, respectively. The cumulative incidence of cancer was significantly higher in MTX- \& biologics-naïve JIA children group (1.19\% vs. $0.43 \%, \mathrm{P}<0.0001)$. The population attributable risk was $23.38 \%$ (95\% CI, $10.56 \%$ - 36.21\%) meaning among the general population, somewhere between $11 \%$ to $36 \%$ of the total risk for cancer was due to JIA status (Table 3).

With mean (SD) duration of follow-up of the JIA subgroups of "biologics-naïve methotrexate group" for 5.93 (2.08) years (2030.08 patient-years at risk), "anti-TNF biologics-containing” 3.46 (1.82) years (386.73 patient-years at risk), and "both methotrexate- and biologics-naïve" 6.60 (1.10) years (16114.16 patient-years at risk), we did not observe a statistically significant increased risk for cancer in JIA subgroups treated with methotrexate (RR 2.02; 95\% CI, $0.67-6.04$ ) or anti-TNF biologics (RR 2.07; 95\% CI, 0.36 - 11.49) (Table 3). The mean duration of drug exposure in years for methotrexate group was 2.97 (2.82) and for anti-TNF inhibitor-containing group 3.05 (1.75).

The indirect standardized incidence rate (SIR) for all types of cancer in the non-JIA comparator cohort defined as ((Observed number of malignancies/Expected number of malignancies $) \times$ crude cancer incidence rate of the national population) was estimated. The crude cancer incidence rate of the national population aged from ten to twenty four years in the year 2008 was 17.10 per 100,000 as documented in the officially published Taiwan Cancer Registry, "Table Seven: Age distribution of cancer morphology by gender and primary anatomic sites 2008" (http://tcr.cph.ntu.edu.tw/main.php?Page=N2). The expected number of incident malignancies was three. Thus, the indirect SIR for all types of cancer in the nonJIA cohort equals $285(50 / 3 \times 17.1)$ per 100,000 . It is higher than the nationwide average age-specific incidence rate for all types of cancer.

Based on the "both methotrexate- and biologics-naïve" subgroup of 2,436 patients with JIA having a mean follow up of 6.6 years, the incidence rate ratio for selected cancer types were calculated. There were increased IRR for leukemia at 7.38 (95\% CI, 2.50 - 22.75), lymphoma 8.30 (95\% CI, $1.23-69.79)$ and other malignancy mostly solid tumor 2.08 (95\% CI, 1.11 - 3.71). However, there were no statistical increase of IRR in soft tissue sarcoma at 11.07 (95\% CI, $0.84-326.4)$ and primary bone cancer $5.53(0.14-215.8)$ (Table 3).

\section{Cox proportional hazard regression models}

After adjustment for age and gender, the aHR for developing malignancy was 3.14 times higher (95\% CI, $1.98-4.98$, $\mathrm{P}<0.0001)$ in children with JIA who had not been exposed to either methotrexate or TNF-alpha inhibitors (Table 4). There were no further statistically significant increase of the risk in terms of aHR in children with JIA treated with 
Table 3 Exposure to methotrexate and/or an anti-TNF biologic in JIA patients and subsequent risk on malignancy development

\begin{tabular}{|c|c|c|c|c|c|c|}
\hline & & & JIA & & Non-JIA & $P$-value \\
\hline & & $\begin{array}{l}\text { MTX use, } \\
\text { biologics-naive }\end{array}$ & $\begin{array}{l}\text { Anti-TNF } \\
\text { biologics-containing }\end{array}$ & $\begin{array}{l}\text { Both MTX- and } \\
\text { biologics-naive }\end{array}$ & & \\
\hline Total & & 344 & $112^{+}$ & 2436 & 11568 & \\
\hline Gender & Female & 144 & 43 & 1087 & 5096 & 0.4849 \\
\hline & Male & 200 & 69 & 1349 & 6472 & \\
\hline Mean age (SD) & & $11.22(3.23)$ & $10.54(3.67)$ & $11.55(3.46)$ & $10.94(3.65)$ & $<0.0001$ \\
\hline Age group (n) & $0-5$ & 20 & 12 & 201 & 932 & $0.0054 \ddagger$ \\
\hline & $6-10$ & 104 & 38 & 557 & 2796 & \\
\hline & $11-15$ & 220 & 62 & 1678 & 7840 & \\
\hline Follow-up year, mean (SD) & & $5.93(2.08)$ & $3.46(1.82)$ & $6.60(1.10)$ & $7.78(0.59)$ & $<0.0001$ \\
\hline $\begin{array}{l}\text { Duration of drug exposure in year, } \\
\text { mean (SD) }\end{array}$ & & $2.97(2.82)$ & $3.05(1.75)$ & NA & NA & 0.78 \\
\hline Malignancy & Yes & 3 & 1 & 29 & 50 & $<0.0001$ \\
\hline & No & 341 & 111 & 2407 & 11518 & \\
\hline Person-years & & 2030.08 & 386.73 & 16114.16 & 89156.74 & \\
\hline Incidence rate ratio $(95 \% \mathrm{Cl})$ & & $2.64(0.65-7.53)$ & $4.61(0.23-23.61)$ & $3.21(2.01-5.05)$ & Ref & \\
\hline Relative Risk (95\% Cl) & & $2.02(0.67-6.04)$ & $2.07(0.36-11.49)$ & $2.75(1.75-4.32)^{*}$ & Ref & \\
\hline $\begin{array}{l}\text { Population attributable risk } \\
(95 \% \mathrm{Cl})\end{array}$ & & $2.85 \%(-3.53-9.24)$ & $1.01 \%(-2.82-4.84)$ & $23.38 \%(10.56-36.21)$ & Ref & \\
\hline Leukemia & Yes & 2 & 0 & 8 & 6 & \\
\hline IRR $(95 \% \mathrm{CI})$ & & - & - & $7.38(2.50-22.75)^{*}$ & Ref & \\
\hline Lymphoma & Yes & 0 & 0 & 3 & 2 & \\
\hline IRR $(95 \% \mathrm{Cl})$ & & - & - & $8.30(1.23-69.79)^{*}$ & Ref & \\
\hline Soft tissue sarcoma & Yes & 0 & 0 & 2 & 1 & \\
\hline IRR (95\% CI) & & - & - & $11.07(0.84-326.4)$ & Ref & \\
\hline Primary bone cancer & Yes & 0 & 0 & 1 & 1 & \\
\hline IRR $(95 \% \mathrm{Cl})$ & & - & - & $5.53(0.14-215.8)$ & Ref & \\
\hline Other malignancy & Yes & 1 & 1 & 15 & 40 & \\
\hline IRR $(95 \% \mathrm{CI})$ & & - & - & $2.08(1.11-3.71)^{*}$ & Ref & \\
\hline
\end{tabular}

Cl: confidence interval; JIA: Juvenile idiopathic arthritis; MTX: methotrexate; NA: not applicable; Ref: reference; SD: standard deviation; TNF: tumor necrosis factor. *statistically significant, $\mathrm{P}<0.05$.

${ }^{\top} 105$ subjects $(93.75 \%)$ previously or currently received MTX treatment.

\#: Kruskal-Wallis statistic.

Chi-square analysis-of-contingency table statistical method was for categorical data such as gender.

Poisson distribution and test-based methods are used to construct the confidence intervals for IRR.

either methotrexate whose aHR, 2.72 (95\% CI, 0.85 - 8.73; $\mathrm{P}=0.0932)$ or TNF-alpha inhibitors whose aHR, 6.05 (95\% CI, $0.82-44.61 ; \mathrm{P}=0.0772$ ) (Table 4). It merits mention that the anti-TNF biologics-containing group in the JIA cohort contained only 112 children.

\section{Discussion}

Through this nationwide population-based retrospective cohort, we demonstrated that the incidence of malignancy was significantly increased approximately 3-fold in Taiwanese children with JIA. There were three cases of

Table 4 Cox proportional hazard regression model showing the adjusted hazard ratio on the risk of developing malignancy in different groups of JIA patients by treatment and non-JIA patients

\begin{tabular}{lllll}
\hline & MTX use, biologics-naive & Anti-TNF biologics-containing & Both MTX-and biologics-naive & Non-JIA \\
\hline aHR & 2.72 & 6.05 & 3.14 & 1 \\
$95 \% \mathrm{Cl}$ & $0.85-8.73$ & $0.82-44.61$ & $1.98-4.98$ & - \\
$P$-value & 0.0932 & 0.0772 & $<0.0001$ & - \\
\hline
\end{tabular}

aHR: adjusted Hazard Ratio by gender and age; Cl: confidence interval; JIA: juvenile idiopathic arthritis; MTX: methotrexate; TNF inhibitor: tumor necrosis factor. 
incident cancer in the "MTX use, biologics-naïve" group, only one in the anti-TNF biologics-containing group and twenty nine in the "both MTX- and biologics-naïve" group, in comparison, there were fifty cases of cancer in the non-JIA comparator group. The cancer types which were found to be statistically increased in terms of the IRR were leukemia (7-fold increase), lymphoma (8-fold) and all other malignancies (2-fold).

To the best of our knowledge, this cohort study presents the first best available estimate of the magnitude of risk for cancer in Asian JIA population. Our results in East Asian children in addition to three other prior large studies using claims database, National Medicaid data, or the Swedish Patient Register National Data, suggest that children with JIA per se is associated with a 2- to 4- fold increase of cancer risk, particularly lymphoproliferative malignancies (Table 1) [18-20]. However, our data did not reveal statistically significant further increase of incident malignancy in children with JIA after a mean (SD) duration of exposure of 2.97 (2.82) years to methotrexate and/or 3.05 (1.75) years to TNF-alpha inhibitors. Although anti-TNF biologics treatment are feared to increase the risk of malignancy particularly lymphoproliferative malignancy such as hepatosplenic T-cell lymphoma (HSTCL) which is the commonest reported subtype of all T-cell lymphoma, this phenomenon is still not yet confirmed in any published prospective cohort study [20,28-33]. One of the explanations may be owing to the inherent susceptible risk already exists in children with JIA.

A recent detailed analysis of 100 cases of T-cell nonHodgkin's lymphoma (NHL) reported to the US FDA disclosed that $68 \%$ of the cases involved exposure to both a TNF-alpha inhibitor and an immunomodulator. Risk of T-cell NHL was higher with concomitant use of TNF-alpha inhibitor with thiopurines (95\% CI 4.98354.09; $\mathrm{P}<0.0001)$ and thiopurines alone $(95 \% \mathrm{CI}$ 8.32-945.38; $\mathrm{P}<0.0001)$ but not with TNF-alpha inhibitor use alone (95\% CI 0.13-10.61; $\mathrm{P}=1.00)$ [34]. Many of those reported cases that lead the FDA to place a black box warning on TNF-alpha inhibitors were in children with inflammatory bowel disease rather in JIA.

The female to male ratio in our JIA cohort was 0.79: 1 . This ratio echoes other prior studies from Asia that in contrast to Caucasian population having female preponderance which ranges from 2: 1 to 3: 1 in most published series, Asian population of JIA has a relative male predominance. The explanation for this sex ratio difference is fairly clear that ERA, an entity of predominantly male and older age of onset, constituted $42 \%$ of the JIA cohort in this study. Our previous study mentioned earlier in the paper found that the proportion of ERA was 37.4\% in the Taiwanese Chinese cohort [9]. In addition, other unique clinical features reported in Asian children are older age of onset, a lower antinuclear antibody (ANA) positivity rate, a lower chronic uveitis incidence and different subtypes of JIA on presentation $[5,6,9]$.

In the JIA cohort, $15.5 \%((344+105) / 2,892)$ of children required methotrexate for aggressive preservation of joint function and control of disease process. And only 3.9\% of the entire JIA cohort were escalated to anti-TNF biologics therapy. In a published nationwide retrospective survey of 570 cases in Japan, $12.8 \%$ of their case series were treated with methotrexate [7]. This may reflect an overall realworld picture of the severity and treatment policy for JIA in East Asia.

\section{Strengths and limitations}

Our study has certain strengths. Because participation in the NHI program is mandatory and all residents of Taiwan can assess a paediatrician rheumatologist without needing a referral, the referral bias is essentially avoided. Loss to follow-up is virtually non-exist because of the country-wide NHI coverage for medical care allowing continuous tracking of an enrollee during relocation or self-transferal. With a large number of age- and gendermatched non-JIA comparators, the cumulative incidence rate of cancer in the control group is considered accurate.

However, the findings of this study need to be interpreted in the context of certain potential limitations. First, many demographic variables were not available, such as family history of cancer, diet and environmental exposures. This is because individual identities are not available due to the de-identification of the individuals within the NHI databases. Second, the disease severity of JIA could not be obtained in this claims study. The risk of over-diagnosis resulted from solely using the ICD-9-CM codes for case identification is likely present due to inability to verify the diagnosis of JIA using the patients' own medical records. We could not be $100 \%$ sure to exclude potentially exist undiagnosed JIA cases in the control group which may result in possible allocation bias. Finally, since this is not an incidence cohort for JIA and left censoring of disease and medication therapy cannot be excluded.

The possibility of a protopathic bias was not completely ruled out although the study design had deployed an exclusion criteria to exclude subjects with pre-existing cancer traceable back to at least one whole year in the medical record by ICD-9-CM codes.

\section{Conclusions}

This nationwide population-based retrospective cohort study of the association between JIA by their treatment allocation and cancer risk with up to 8 years follow-up reveals that this East Asian children population with JIA is associated with a 3-fold increased risk of malignancy $(I R R=3.21$ and adjusted $H R=3.14)$ and there is no 
statistically significant increased risk in these patients with exposure to methotrexate and/or TNF inhibitors. The risk for other solid tumors was statistically significantly increased by 2 -fold.

\section{Competing interests}

The authors declare that they have no competing interests.

\section{Authors' contributions}

JLH, VCK and JTH conceived and designed the work; JTH, JJG, LZZ participated in acquisition of data, and together with JLH, VCK, JTH, KWY and CWC in analysis and interpretation of data. VCK and JLH drafted the article. JTH was responsible for acquisition of research fund for this work. VCK, JTH and JLH gave final approval of the version to be published. All authors read and approved the final manuscript.

\section{Authors' information}

$\mathrm{JLH}$ and $\mathrm{KWY}$ are professors of pediatric rheumatology and experts in juvenile idiopathic arthritis. VCK is a medical oncologist and medical informatician who is also teaching evidence-based medicine to junior medical staffs. JTH and CWC are experts in information engineering and big data management.

\section{Acknowledgments}

We are immensely thankful to the Bureau of National Health Insurance, Department of Health, and National Health Research Institutes for kindly providing the raw data for analysis. The interpretation and conclusions contained herein do not represent those of the Bureau of National Health Insurance, Department of Health, or National Health Research Institutes Taiwan. The authors would like to thank the National Science Council of the Republic of China (Taiwan) for financially supporting this research.

\section{Funding}

This work was partly supported by grants from the National Science Council of the Republic of China under contract number NSC 101-2221-E-008-125-MY3. The funders had no role in study design, data collection and analysis, decision to publish, or preparation of the manuscript. No grants are from the NIH of the US.

\section{Author details}

${ }^{1}$ Population-Health and Clinical Informatics Research Group, Department of Biomedical Informatics, Asia University Taiwan, Taichung, Taiwan. ${ }^{2}$ Division of Medical Oncology, Department of Internal Medicine, Kuang Tien General Hospital, Taichung, Taiwan. ${ }^{3}$ Department of Computer Science and Information Engineering, National Central University, Chungli, Taiwan. ${ }^{4}$ Division of Paediatric Allergy Asthma and Rheumatology, Department of Paediatrics, Chang Gung Memorial Hospital, Linkou, Taiwan. ${ }^{5}$ Chang Gung University College of Medicine, Taoyuan, Taiwan. ${ }^{6}$ Department of Information Management, Hsing Wu University, New Taipei City, Taiwan.

Received: 16 February 2014 Accepted: 21 August 2014

Published: 29 August 2014

\section{References}

1. Petty RE, Southwood TR, Manners P, Baum J, Glass DN, Goldenberg J, He X, Maldonado-Cocco J, Orozco-Alcala J, Prieur AM, Suarez-Almazor ME, Woo P: International league of associations for rheumatology classification of juvenile idiopathic arthritis: second revision, Edmonton, 2001. J Rheumatol 2004, 31(2):390-392.

2. Helmick CG, Felson DT, Lawrence RC, Gabriel S, Hirsch R, Kwoh CK, Liang MH, Kremers HM, Mayes MD, Merkel PA, Pillemer SR, Reveille JD, Stone JH: Estimates of the prevalence of arthritis and other rheumatic conditions in the United States. Part I. Arthritis Rheum 2008, 58(1):15-25.

3. Sacks JJ, Helmick CG, Luo YH, llowite NT, Bowyer S: Prevalence of and annual ambulatory health care visits for pediatric arthritis and other rheumatologic conditions in the United States in 2001-2004. Arthritis Rheum 2007, 57(8):1439-1445.

4. Symmons DP, Jones M, Osborne J, Sills J, Southwood TR, Woo P: Pediatric rheumatology in the United Kingdom: data from the British pediatric rheumatology group national diagnostic register. J Rheumatol 1996, 23(11):1975-1980
5. Huang JL: New advances in juvenile idiopathic arthritis. Chang Gung Med J 2012, 35(1):1-14.

6. Huang JL, Yao TC, See LC: Prevalence of pediatric systemic lupus erythematosus and juvenile chronic arthritis in a Chinese population: a nation-wide prospective population-based study in Taiwan. Clin Exp Rheumatol 2004, 22(6):776-780.

7. Fujikawa S, Okuni M: Clinical analysis of 570 cases with juvenile rheumatoid arthritis: results of a nationwide retrospective survey in Japan. Acta Paediatr Jpn 1997, 39(2):245-249.

8. Manners PJ, Bower C: Worldwide prevalence of juvenile arthritis why does it vary so much? I Rheumatol 2002, 29(7):1520-1530.

9. Shen CC, Yeh KW, Ou LS, Yao TC, Chen LC, Huang JL: Clinical features of children with juvenile idiopathic arthritis using the ILAR classification criteria: a community-based cohort study in Taiwan. J Microbiol Immunol Infect 2013, 46(4):288-294.

10. Anink J, Otten MH, Prince FH, Hoppenreijs EP, Wulffraat NM, Swart JF, Ten Cate $R$, van Rossum MA, van den Berg JM, Dolman KM, Koopman-Keemink Y, Armbrust W, Kamphuis S, van Pelt PA, Gorter SL, van Suijlekom-Smit LW: Tumour necrosis factor-blocking agents in persistent oligoarticular juvenile idiopathic arthritis: results from the Dutch arthritis and biologicals in children register. Rheumatology (Oxford) 2013, 52(4):712-717.

11. Bracaglia C, Buonuomo PS, Tozzi AE, Pardeo M, Nicolai R, Campana A, Insalaco A, Cortis E, de Benedetti F: Safety and efficacy of etanercept in a cohort of patients with juvenile idiopathic arthritis under 4 years of age. J Rheumatol 2012, 39(6):1287-1290.

12. Gutierrez-Suarez R, Burgos-Vargas $R$ : The use of methotrexate in children with rheumatic diseases. Clin Exp Rheumatol 2010, 28(5 Suppl 61):S122-S127.

13. Kemper AR, Van Mater HA, Coeytaux RR, Williams JW Jr, Sanders GD: Systematic review of disease-modifying antirheumatic drugs for juvenile idiopathic arthritis. BMC Pediatr 2012, 12:29.

14. Lovell J, Giannini H, Reiff A, Cawkwell D, Silverman D, Nocton J, Stein D, Gedalia A, llowite T, Wallace A, Whitmore J, Finck BK: Etanercept in children with polyarticular juvenile rheumatoid arthritis. Pediatric Rheumatology Collaborative Study Group. N Engl J Med 2000, 342:763-769.

15. Beukelman T, Patkar NM, Saag KG, Tolleson-Rinehart S, Cron RQ, DeWitt EM, Ilowite NT, Kimura Y, Laxer RM, Lovell DJ, Martini A, Rabinovich CE, Ruperto N: 2011 American College of Rheumatology recommendations for the treatment of juvenile idiopathic arthritis: initiation and safety monitoring of therapeutic agents for the treatment of arthritis and systemic features. Arthritis Care Res 2011, 63(4):465-482.

16. Bernatsky S, Rosenberg AM, Oen KG, Duffy CM, Ramsey-Goldman R, Labrecque J, St Pierre Y, Clarke AE: Malignancies in juvenile idiopathic arthritis: a preliminary report. J Rheumatol 2011, 38(4):760-763.

17. Thomas E, Brewster DH, Black RJ, Macfarlane GJ: Risk of malignancy among patients with rheumatic conditions. Int J Cancer 2000, 88(3):497-502.

18. Simard J, Neovius M, Hagelberg S, Askling J: Juvenile idiopathic arthritis and risk of cancer: a nationwide cohort study. Ann Rheum Dis 2010, 69(Suppl 3):81

19. Nordstrom BL, Mines D, Gu Y, Mercaldi C, Aquino P. Harrison MJ: Risk of malignancy in children with juvenile idiopathic arthritis not treated with biologic agents. Arthritis Care Res 2012, 64(9):1357-1364.

20. Beukelman T, Haynes K, Curtis JR, Xie F, Chen L, Bemrich-Stolz CJ, Delzell E, Saag KG, Solomon DH, Lewis JD: Rates of malignancy associated with juvenile idiopathic arthritis and its treatment. Arthritis Rheum 2012, 64(4):1263-1271.

21. Kok VC, Horng JT, Lin HL, Chen YC, Chen YJ, Cheng KF: Gout and subsequent increased risk of cardiovascular mortality in non-diabetics aged 50 and above: a population-based cohort study in Taiwan. BMC Cardiovasc Disord 2012, 12:108.

22. Kok VC, Horng JT, Agustriawan D: Statins use increases the risk of urinary tract cancer: preliminary results of a nationwide population-based case-control study. Asia Pac J Clin Oncol 2012, 9(2):190-191.

23. Chen TA, Kang HY, Chang HC, Lin WC, Chao TM, Horng JT: Gender differences in colorectal cancer during the past 20 years in Taiwan. Int $\mathrm{J}$ Colorectal Dis 2012, 27(3):345-353.

24. Chen TA, Horng JT, Lin WC: Metachronous colorectal cancer in Taiwan: analyzing 20 years of data from Taiwan Cancer Registry. Int I Clin Oncol 2013, 18(2):267-272.

25. Chang CW, Kok VC, Tseng TC, Horng JT, Liu CE: Diabetic patients with severe sepsis admitted to intensive care unit do not fare worse than non-diabetic patients: a nationwide population-based cohort study. PLoS One 2012, 7(12):e50729. 
26. Yeh KW, Yu CH, Chan PC, Horng JT, Huang JL: Burden of systemic lupus erythematosus in Taiwan: a population-based survey. Rheumatol Int 2013, 33(7):1805-1811.

27. Yu HH, Chen PC, Wang LC, Lee JH, Lin YT, Yang YH, Lin CP, Chiang BL: Juvenile idiopathic arthritis-associated uveitis: a nationwide population-based study in Taiwan. PLoS One 2013, 8(8):e70625.

28. Cron R, Beukelman T: Guilt by association - what is the true risk of malignancy in children treated with etanercept for JIA? Pediatr Rheumatol 2010, 8(1):23.

29. Diak P, Siegel J, La Grenade L, Choi L, Lemery S, McMahon A: Tumor necrosis factor alpha blockers and malignancy in children: forty-eight cases reported to the Food and Drug Administration. Arthritis Rheum 2010, 62:2517-2524.

30. Horneff G, Foeldvari I, Minden K, Moebius D, Hospach T: Report on malignancies in the German juvenile idiopathic arthritis registry. Rheumatology (Oxford) 2011, 50(1):230-236.

31. Lehman TJA: Should the food and drug administration warning of malignancy in children receiving tumor necrosis factor a blockers change the way we treat children with juvenile idiopathic arthritis? Arthritis Rheum 2010, 62(8):2183-2184.

32. Onel $\mathrm{KB}$, Onel $\mathrm{K}$ : Tumor necrosis factor inhibitors and cancer in juvenile idiopathic arthritis: Disentangling the web. Arthritis Rheum 2012, 64(4):966-969.

33. Minden $\mathrm{K}$, Niewerth M, Zink A, Seipelt E, Foeldvari I, Girschick H, Ganser G, Horneff G: Long-term outcome of patients with JIA treated with etanercept, results of the biologic register JuMBO. Rheumatology (Oxford) 2012, 51(8):1407-1415.

34. Deepak P, Sifuentes H, Sherid M, Stobaugh D, Sadozai Y, Ehrenpreis ED: T-cell non-Hodgkin's lymphomas reported to the FDA AERS with tumor necrosis factor-alpha (TNF-alpha) inhibitors: results of the REFURBISH study. Am J Gastroenterol 2013, 108(1):99-105.

doi:10.1186/1471-2407-14-634

Cite this article as: Kok et al.: Population-based cohort study on the risk of malignancy in East Asian children with Juvenile idiopathic arthritis. BMC Cancer 2014 14:634.

\section{Submit your next manuscript to BioMed Central and take full advantage of:}

- Convenient online submission

- Thorough peer review

- No space constraints or color figure charges

- Immediate publication on acceptance

- Inclusion in PubMed, CAS, Scopus and Google Scholar

- Research which is freely available for redistribution 